\title{
Building's Solar Chimney: Ambient Obstacle and Crosswind in a Tropical Country
}

\author{
Abraham Seno Bachrun \\ Department of Built Environment and \\ Energy Engineering \\ School of Engineering and Architecture \\ Wuhan University of Technology \\ Wuhan, P.R. China \\ abraham.seno@mercubuana.ac.id
}

\author{
Ting Zhen Ming \\ Department of Built Environment and \\ Energy Engineering \\ School of Engineering and Architecture \\ Wuhan University of Technology \\ Wuhan, P.R. China \\ tzming@whut.edu.cn
}

\author{
Sri Kurniasih \\ Architecture Department \\ Universitas Budi Luhur \\ Jakarta, Indonesia \\ sri.kurniasih@budiluhur.ac.id
}

\begin{abstract}
The abundant of solar in tropical countries is an advantage of utilizing solar energy. One of them is the use of the stack effect through the solar chimney. Experts have widely discussed the use of solar chimney in buildings. It concluded that solar chimney in buildings was able to increase the air velocity inside the buildings by $35 \%$. To find out the overall performance of the solar chimney, crucial to find out more about ambient obstacle will affect the inlet and crosswind affected by the chimney to surrounding buildings and the environment, especially for an office building with solar chimney in Jakarta, Indonesia. This research aims; first, to investigate the effect of different ambient crosswind on the building with solar chimney. Second, to investigate the effective distance from the buildings with solar chimney with surrounding buildings to obtain maximum performance from the solar chimney system's inlet, which forces wind into the building. The method used is a numerical experiment with Ansys-CFX. Wind velocity and pressure produced in buildings with solar chimney are variable compared to the speed of buildings without a solar chimney to get effective distance with an obstacle. Also, the wind velocity that occurs around the outlet is a variable to assess how the crosswind influences the chimney on surrounding buildings and the environment. Ambient crosswind can reduce SC performance 5-10\%, while obstacle in front of inlet will reduce the performance to $35 \%$ depend to the clearance distance. The results are the clear will be a guideline for 8-10 story buildings with a natural ventilation system which uses the solar chimney as a passive ventilation device. The results also compare with the regional regulation.
\end{abstract}

Keywords: passive ventilation strategy, building's solar, ambient crosswind

\section{INTRODUCTION}

In tropical climates, buildings, generally, designed with a natural ventilation system that maximizes wind speed to cool building structures or achieve physiological comfort. Some features of building design in tropical climates include wide openings, roofs with sufficient slope angles, surfaces, and maximizing the shade around the building. In addition to paying attention to wind speed, the environment around the building, and ambient crosswind also considered. Thermal comfort is mainly given by the temperature of the cold room, reducing the water content supplied to the room, and providing clean air, especially in humid tropical areas[1].

Indonesia is one of the tropical countries with a humid climate. According to the Indonesian National Standard
(SNI), the comfort conditions in Indonesia are room temperature $25^{\circ} \mathrm{C}$ and relative humidity $54 \%$ to $66 \%$ [2]. One of the development policies that are oriented towards (ASEAN Economic Community) AEC 4.0 is to promote aspects of sustainable development. The use of passive ventilation is important in sustainable development. Modern passive ventilation is a system that combines passive ventilation systems with modern building designs with the utilization of the climate itself (humid tropical climate). The effect of air movement with cross ventilation is not enough to create physiological cooling of the building. The air velocity associated with natural convection is relatively small, usually not more than $2 \mathrm{~m} / \mathrm{s}$. The passive design strategy is a way to save energy through passive utilization of solar energy, that is, without converting solar energy into electricity[1,3]. The passive design relies more on the ability of architects how the design of the building by itself can "anticipate" external climate problems.

The main objective of the passive solar design strategy in the tropical area is to maximize the potential for an abundance of solar radiation to improve the heating/cooling of buildings. One of them is by utilizing the stack ventilation strategy. Ventilation stress is caused by stack pressure or buoyancy at the opening in terms of variations in water density as a result of differences in opposite openings. Double Skin Façade (DSF) and Solar Chimney (SC) are technologies that use the principle of the effect of pressure differences between two openings with vertical gradients. Experimental with the help of a simulation program is considered capable in solving cases of airflow problems in medium-rise buildings with SC. The phenomenon produced in this study involves the difference in pressure and temperature simultaneously in every movement of airflow in buildings with SC. It will raise its concern for simulating the stack effect (without a pressure) when the climate in the humid tropics experiences tend to very low (near zero) airflow in the building environment. Determination of the appropriate simulation software in the case of research also needs to be studied first as a first step in testing the stack effect.

There are two methods in testing the performance of the effectiveness of DSF: physical testing and simulation (nonphysical) software testing. All testing methods are, basically, conceptual models to visualize an object. In physical modeling, the form of copy built from an object that represents an object. The physical can be a scaled model and 
actual size. Both can be applied depending on the availability of funds and the complexity of the real object. Simulation software testing adapts building copies and environmental conditions with a non-tangible approach that is controlled by mathematical equations[5]. Several advantages in simulation methods are proposed by which are being able to capture the complexity of reality, be able to reveal unexpected results/various predictions, and enable environmental simulations to reveal correlation relationships quickly[6].

The application of DSF technology has been developing since the 1990s[7]. A number of benefits of the double-skin facade, including reducing the building's internal heat, longterm building's financing, saving energy, reducing noise emissions, reducing frontal pressure in multi-storey buildings/stream distribution, minimizing sick building syndrome, and representation of building facade technology, previous research compared with a single-skin facade has been done a lot [7-15]. Hamza, Gratia \& Herde, and Sangkertadi \& Suryono also the previous researchers who conducted studies related to natural airflow for cases of buildings with DSF. The study took the case of typical office building modeling in the study area, then carried out the analysis with the help of simulations to see the performance of the airflow. Several experimental, numerical and theoretical investigations have contributed to the understanding of the use of solar chimneys in today's buildings, related to various aspects (shape, height, material, location, weather, and other aspects).

The investigation of the effects of the number of solar chimneys, the chimney height, the width of the air gap, and the orientation of the chimney in natural ventilation in space has been done experimentally by Hassanein et al[16]. Ding, et al. examined the performance of natural ventilation of the highlighted double skin[17]. Ding concluded that increasing the SC height made more ventilation rates and also advantageous to obtain a favorable distribution of pressure differences. Furthermore, further analysis was carried out by developing experiments with the help of simulations. The density of buildings in urban areas is one of the principal factors that affect microclimate conditions and determine ventilation conditions and air temperature. The symptoms of urban warming are mainly somewhat influenced by the density of the city rather than the size of the city itself, the denser the building, the worse the ventilation conditions[18].

On the other hand, high density also provides an advantage in reducing sunlight from buildings during the tropical period. The effect of city density on ventilation conditions also depends on wind conditions, space arrangement, and building height[19]. Abraham and Ming, through his research, discussed the use of SC in buildings in the tropics (Jakarta)[20]. It concluded that solar chimney in buildings was able to increase the wind velocity in buildings by $35 \%$. They carried out his research on an 8-story building prototype located in the tropics (Jakarta) but only limited to the shape, height, and performance aspects of the inlet and width of the chimney.

Furthermore, it is essential to know about the influence of building density as an obstacle in front of the inlet, considering the location of Jakarta is very famous for its density of buildings. This study aims first to investigate the effective clearance of buildings with solar chimney with surrounding buildings to obtain maximum performance from the solar chimney inlet system in suctioning air into the building. The two investigate the effect of the wind coming out of the outlet chimney towards the ambient, as well as the wind through the chimney. This study is limited to residential buildings with 8-10 floors. The location of this study is in the humid tropical area, especially in Jakarta. The level of building density that is the location of this study is high density.

\section{METHODOLOGY}

This study uses mixed-method research with a sequential exploratory approach strategy. The strategy involves collecting and analyzing qualitative data in the first stage. Furthermore, the research followed by the collection and analysis of quantitative data in the second stage based on the results of the first stage[21]. The first step is to validate the use of simulation software that is suitable for testing the behavior of wind velocity in buildings. After the validation process for selecting the type of simulation software is carried out, then the research is directed at the process of programming stages which begins with the determination of the configuration model of middle-rise buildings with SC as the simulation object. The results of the programming simulation will also show as an effort to successfully use the software and prove the performance of the ambient crosswind to the inlets in the humid tropics. In this case, wind behavior is a condition of air pressure, air velocity, and air movement patterns caused by the environment (surrounding buildings) before entering into the system (building) caused by the stack effect.

\section{A. Validation of the Use of Simulation Programs}

Based on related studies involving airflow, CFD programs are the most commonly used programs. Tuakia states that CFD (Computational Fluid Dynamic) is indeed a software program that has many uses in predicting fluid flow, heat transfer, chemical reactions, and other phenomena by solving mathematical equations. In the simulation process, there is a simplification, but the physical condition of the building configuration approached with real conditions.

\section{B. Maintaining the Integrity of the Specifications}

In the results of research conducted by Abraham and Ming, the design of SC building configurations that adapt the climate (especially for humid tropical airflow) must pay attention to aspects of the SC form, placement of SC, inlet, material selection, and consideration of shading devices[20]. All forms of parameter determination have been reviewed from various previous research sources, to obtain modeling assumptions such as Figure 1. In this simulation, the 8-story office model assumed to locate in Jakarta, or around $6^{\circ} 12 \mathrm{~S}$, $106^{\circ} 49^{\prime} \mathrm{E}$ with medium to high-density levels. Each floor has the same room (assuming it is a rented room). Office buildings use Solar Chimney (SC) with an orientation towards the north (negative $\mathrm{x}$-axis). SC has a $1000 \mathrm{~mm}$ gap and a clear-glass collector. Solar will heat a heat wall behind the collector glass wall.

Wind flow, induced through the inlet located on the south side of the building ( $x$ positive axis). The inlet is at the bottom of the room on each floor. From the inlet, the wind will induced towards the SC gap through the SC gap inlet at 


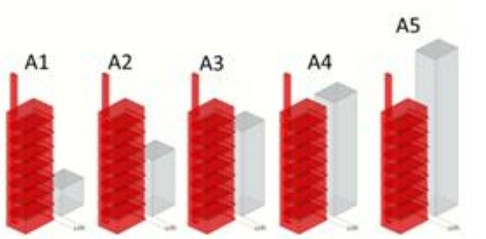

the top of the room. After going through the SC gap, wind will exit through the SC outlet. The model used is the same as the previous research. In this simulation, the building prototype has a total width of $13.2 \mathrm{~m}$ with a floor to floor height of $4 \mathrm{~m}, 8 \mathrm{~m}$ thick. The prototype has an enclosure with a size of $50 \mathrm{~m}$ from the object ( $\mathrm{y}$ and $\mathrm{z}$ positive axis), and $120 \mathrm{~m}$ on the $\mathrm{x}$-axis as shown in Figure 1 below.

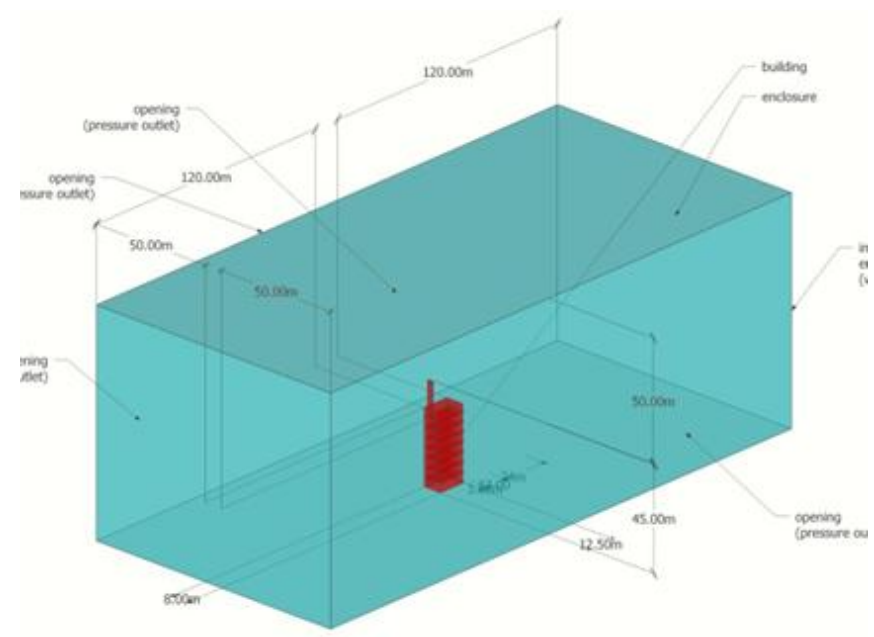

Fig 1.Geometric of building with SC and the enclosure

Several studies have been known to utilize CFD as a basic program in analyzing airflow. The study conducted by Hamza et al. compared the performance of three double glass sheath configurations that apply to summer conditions in temperate climate[12]. The researcher used the help of CFD simulation to compare the air velocity profile in front of the inlet due to direct or after exposure to wind after the building in front of the inlet. At the start of the simulation, researchers examined the behavior of the wind (wind velocity and pressure) from the environment based on measurements of wind conditions in the field. The wind is assumed to originate from the south side of the building (positive $\mathrm{x}$ axis), leading to the inlet side of the building. The wind speed used as the base on field measurements is from $0 \mathrm{~m} / \mathrm{s}$ to the maximum speed in Jakarta $2 \mathrm{~m} / \mathrm{s}$. The second stage is to put the building obstacle in front of the inlet with a distance of $3 \mathrm{~m}$ (A-assumed to separate by a road), $12 \mathrm{~m}$ (Bassumed to be one building apart), and $24 \mathrm{~m}$ (C-assumed 2 buildings). The wind speed used is $2 \mathrm{~m} / \mathrm{s}$ (assuming maximum wind speed at the location). Figure 2 show each obstacle which has a different height: two floors (1), four floors (2), six floors (3), eight floors (4), and parallel to the chimney (5).
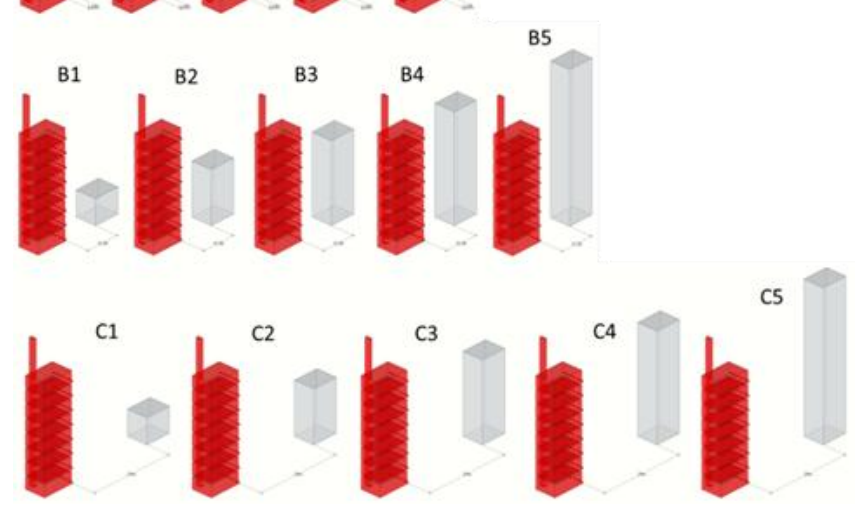

Fig 2. Obstacle in front of inlet configurations

\section{Mathematics equation}

ANSYS-CFX Version 16 used for simulation purposes in this study. ANSYS-CFX Version 16 uses the unsteady Navier-Stokes equation in their conservation form to solve a series of equations. The instantaneous equation of mass (continuity), Navier-stokes, momentum, and energy conservation presented below

Mass Continuity equation:

$$
\frac{\partial \rho}{\partial t}+\frac{\partial\left(\rho u_{i}\right)}{\partial x_{i}}=0
$$

Navier-Stokes equation:

$$
\begin{gathered}
\rho \frac{d u}{d t}=-\frac{\partial P}{\partial r}+\frac{\partial}{\partial r}\left[2 \mu \frac{\partial u}{\partial r}+\mu^{\prime} \vec{\nabla} \cdot \vec{v}\right] \\
+\frac{\partial}{\partial z}\left[\mu\left(\frac{\partial u}{\partial z}+\frac{\partial v}{\partial r}\right)\right] \\
+\frac{2 \mu}{r}\left(\frac{\partial u}{\partial r}-\frac{v}{r}\right) \\
\rho \frac{d v}{d t}=-\frac{\partial P}{\partial r}+\rho g+\frac{\partial}{\partial r}\left[2 \mu \frac{\partial v}{\partial z}+\mu^{\prime} \vec{\nabla} \cdot \vec{v}\right] \\
+\frac{1}{r} \frac{\partial}{\partial r}\left[\mu\left(\frac{\partial u}{\partial z}+\frac{\partial v}{\partial r}\right)\right]
\end{gathered}
$$

Momentum Conservation equation:

$$
\frac{\partial y}{\partial x_{j}}\left(\rho u_{i} u_{j}\right)=-\frac{\partial p}{\partial x_{j}}+S_{M}
$$

Energy Conservation equation:

$$
\begin{aligned}
\frac{\partial y}{\partial x_{j}}\left(\rho u_{i} h_{\text {total }}\right)= & -\frac{\partial p}{\partial x_{i}}+\left(\lambda \frac{\partial T}{\partial x_{i}}\right)+u_{i} S_{M} \\
& +S_{E}
\end{aligned}
$$

For SC in buildings, we consider the fluid flow in it to be natural convection caused by solar radiation that heats the heat wall through glass walls. A criterion number that can measure the intensity of buoyancy-induced flow is the Rayleigh number defined in Eq. (1). The density variations in whole computational models are so small that they can be neglected, so it is necessary to use the Boussinesq approach without causing more significant errors. The turbulent 
mathematical model needs to be chosen to describe the fluid flow in SC.

\section{Boundary Condition}

Gravitational acceleration was set at $-9.81 \mathrm{~m} / \mathrm{s} 2$ at the $\mathrm{y}-$ axis. The turbulence model is $\mathrm{k}-\varepsilon$ with full buoyancy effect used to model the turbulent flow. The enclosure inlet is conditioned to have various wind velocity $(0-2 \mathrm{~m} / \mathrm{s})$ where the outlet is conditioned as an opening (using a pressure outlet as its setting). The inlet and outlet in the building are conditioned as a pressure inlet/outlet, so the wind velocity input is set at $0 \mathrm{~m} / \mathrm{s}$. Other elements in the building are conditioned similar to the previous research (Glass wall set with $305 \mathrm{~K}$ temperature and heat wall set with $850 \mathrm{~W} / \mathrm{m} 2$ ). While air density was set as Boussinesq in $1.205 \mathrm{~kg} / \mathrm{m} 3$, thermal expansion coefficient set at 3.41e-03 $1 / \mathrm{K}[22]$ as shown table 1 below.

TABLE I. BOUNDARY CONDITION OF THE SIMULATION

\begin{tabular}{lll}
\hline Place & Type & Value \\
\hline Room inlet & Pressure inlet & $\mathrm{P}_{\mathrm{r}, \mathrm{i}}=0 \mathrm{~Pa}, \mathrm{~T}_{0}=293 \mathrm{~K}$ \\
\hline Chimney outlet & Pressure outlet & $\mathrm{P}_{\mathrm{r}, 0}=0 \mathrm{~Pa}$ \\
\hline Glass wall & Temperature & $305 \mathrm{~K}$ \\
\hline Heat wall & Heat flux wall & $800 \mathrm{~W} / \mathrm{m} 2$ \\
\hline Others wall & Adiabatic wall & $\mathrm{q}=0 \mathrm{~W} / \mathrm{m} 2$ \\
\hline Enclosure wall & Velocity inlet & $\mathrm{P}_{\mathrm{r}, \mathrm{i}}=0 \mathrm{~Pa}, \mathrm{~T}_{0}=293 \mathrm{~K}$ \\
\hline Opening enclosure & Pressure outlet & $\mathrm{Pr}, 0=0 \mathrm{~Pa}$ \\
\hline
\end{tabular}

\section{RESULTS AND DISCUSSION}

In the first stage, the simulation compares the exposure to different wind speeds in the building and its effects after building.

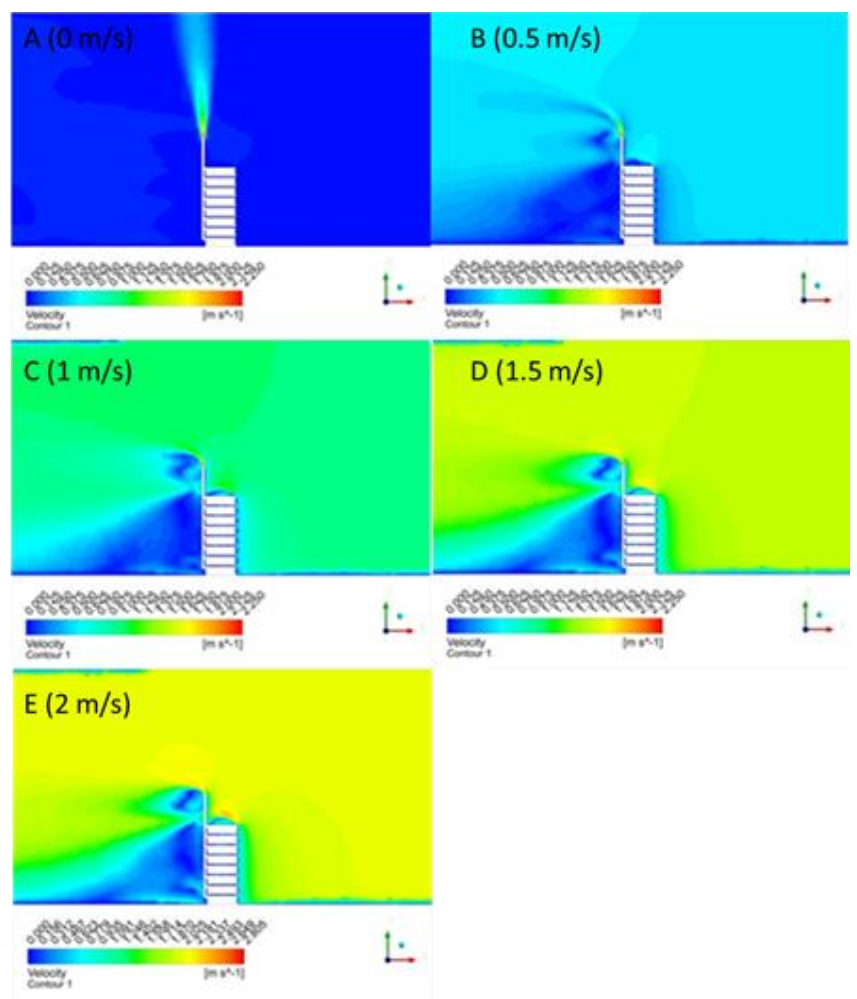

Fig 3. Pressure of ambient crosswind for building with SC without obstacle

The Figure 3 above shows a comparison of the contours of the magnitude of the velocity in the entire simulation area when the transverse ambient velocity increases from 0 to 2 $\mathrm{m} / \mathrm{s}$ and the intensity of solar radiation $\mathrm{G}$ remains $850 \mathrm{~W} / \mathrm{m} 2$, continuously. Wind flows from the SC outlet with a speed of $2.25 \mathrm{~m} / \mathrm{s}$ vertically exiting the SC. The wind flow in the system (building) has been explained in Abraham's previous research, where the air from inside the room will be induced due to heating of heatwall by sunlight entering through glass wall and exiting through the chimney outlet of $2.25 \mathrm{~m} / \mathrm{s}$ (without the presence of ambient crosswind).

At $0 \mathrm{~m} / \mathrm{s}$ crosswind flow, no external wind blows horizontally, the wind coming out of the SC blows vertically to the ambient. There is very little wind coming into the building inlet (not reaching $0.2 \mathrm{~m} / \mathrm{s}$ ). However, when ambient crosswind increases to $0.5 \mathrm{~m} / \mathrm{s}$, shown in Figure 3.b, negative effects can saw: airflow in the north of the building (negative $\mathrm{x}$-axis) tends to remain negative (not moving far from $0 \mathrm{~m} / \mathrm{s}$ ) and the outflow from the chimney outlet also tilts toward the negative $\mathrm{x}$-axis due to ambient crosswind. The same phenomenon occurs when the ambient crosswind speed at the chimney outlet is $1 \mathrm{~m} / \mathrm{s}$ as shown in Fig. 3.c. However, the wind released by the SC through output decreases by $5-6 \%$ (around 1.9-2.1 $\mathrm{m} / \mathrm{s}$ maximum wind velocity) along with increasing ambient crosswind velocity.

However, when the ambient crosswind reaches $1.5 \mathrm{~m} / \mathrm{s}$ (or more), as shown in Figure. 3.d and 3.e, SC returned to its initial performance, and the peak velocity of the chimney outlet airflow returned to $2.25 \mathrm{~m} / \mathrm{s}$, beyond our expectations according to the previous downward influence of ambient crosswind. Thus we can find that the ambient crosswind has a two-sided effect on the solar chimney and the system of the down-and-up performance of the velocity of airflow in the chimney. For this reason, it can be concluded that the performance of solar chimney in buildings at G $850 \mathrm{~W} / \mathrm{m} 2$ (maximum radiation in Jakarta) is at the ambient crosswind 0 $\mathrm{m} / \mathrm{s}$ OR above $1 \mathrm{~m} / \mathrm{s}$. The same is true for other buildings, especially on the north side of the building with SC. There is a large negative airflow especially at the ambient crosswind $0.5-1 \mathrm{~m} / \mathrm{s}$. When the ambient crosswind touches the $1.5 \mathrm{~m} / \mathrm{s}$ number, this negative airflow slowly begins to disappear.

The second stage of simulation is to place the building as an obstacle in front of the inlet system (positive $\mathrm{x}$-axis). The air still enters through the inlet, only in front of the inlet is blocked by obstacle with a distance of 3,12 and $24 \mathrm{~m}$. Each has a height of two, four, six, eight floors, and parallel to the chimney. This experiment is intended to see the effect of the obstacle as a representation of the actual conditions of building density in urban areas, then see effective clearance. The parameters seen are wind velocity and wind pressure. At this stage, the $\mathrm{x}$-axis aligned with the direction of the ambient crosswind speed, the $\mathrm{z}$-axis is in the direction of the building's width, while the $\mathrm{z}$-axis represents the vertical direction of the building. It should be noted that the ambient wind fixed at a maximum velocity of $2 \mathrm{~m} / \mathrm{s}$. As mentioned in the work of previous studies, the main factors that influence the SC characteristics in buildings are solar radiation, ambient crosswind, and conditions around the inlet, where the ambient crosswind significantly influences the key SC parameters in the building. In this analysis, solar radiation was given as $850 \mathrm{~W} / \mathrm{m} 2$; the effect of the obstacle in front of the inlet on the performance of the air going into the inlet analyzed. 
The Figure 5 above explains the previous paragraph, the
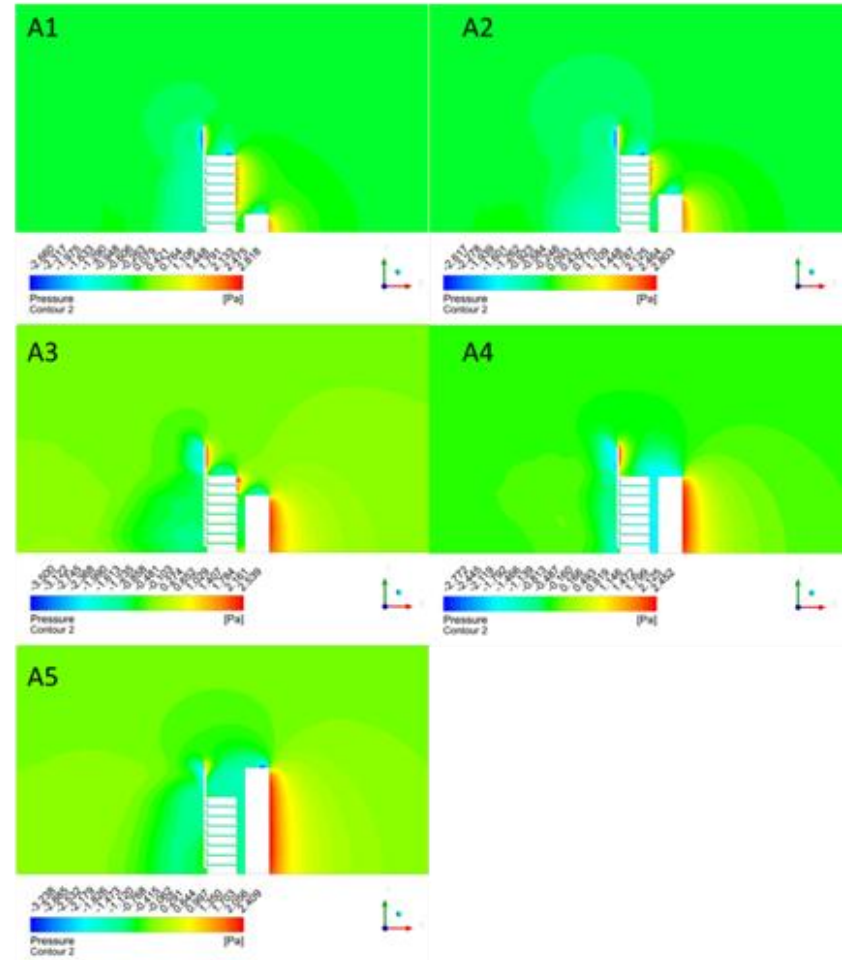

Fig 4. Pressure of ambient crosswind for building with SC with $3 \mathrm{~m}$ in front of inlet's obstacle A1 (two floors obstacle), A2 (four floors obstacle), A3 (six floor obstacle), A4 (eight floors obstacle), and A5 (chimney's height obstacle)

The Figure 4 above shows a contour comparison of the magnitude of the pressure due to the ambient crosswind from the positive $\mathrm{x}$ to the negative $\mathrm{x}$ at $2 \mathrm{~m} / \mathrm{s}$ with the obstacle $3 \mathrm{~m}$ in front of the inlet. In figure A1 to A3, the difference is not very visible (tends to be stable), the pressure that occurs in front of the inlet is almost close to $0 \mathrm{~Pa}$. This pressure suppresses the SC performance in buildings by $30-35 \%$. In the A4 and A5 images, the pressure in front of the inlet happens below $0 \mathrm{~Pa}$ (minus), and of course it will reduce SC performance by $70 \%$. The maximum wind velocity that can be generated at the end of the SC is only $1.7 \mathrm{~m} / \mathrm{s}$, and the wind velocity in space only reaches $0.36 \mathrm{~m} / \mathrm{s}$. SC performance decreases to $70 \%$ because the inlet's front clearance is less wide so that the air induced into space is reduced.

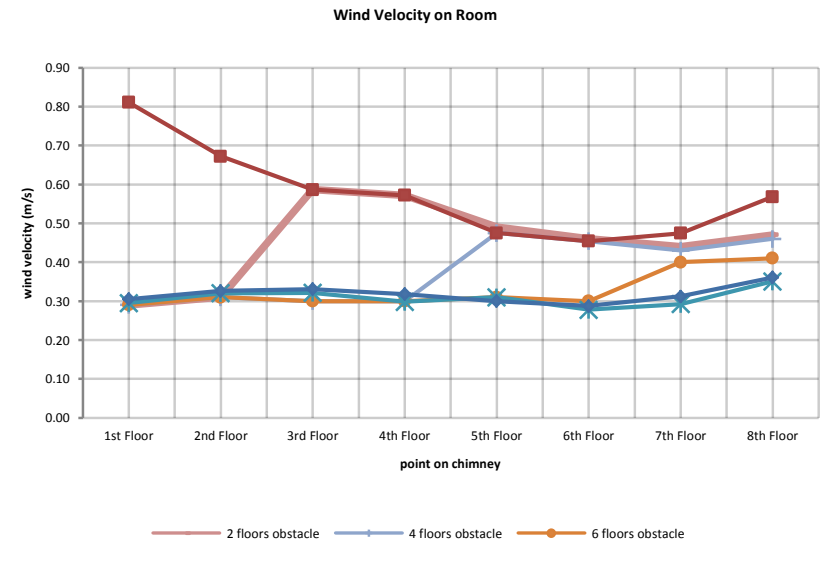

Fig 5. Graphic average wind velocity in building with $\mathrm{SC}$ with $3 \mathrm{~m}$ in front of inlet's obstacle performance of SC in a building when it induces wind when the obstacle is $3 \mathrm{~m}$ from the inlet. SC performance tends to be good when the obstacle building only blocks two floors (A1 \& A2). The performance tends to be stable when the obstacle blocks the inlet from 6 floors (A3, A4, and A5), but tends to be below the standard (maximum $0.36 \mathrm{~m} / \mathrm{s}$ ).

The next step is to widen the clearance of the inlet with the obstacle from $3 \mathrm{~m}$, to $12 \mathrm{~m}$ or $2 \mathrm{x}$ the width of the building with SC.

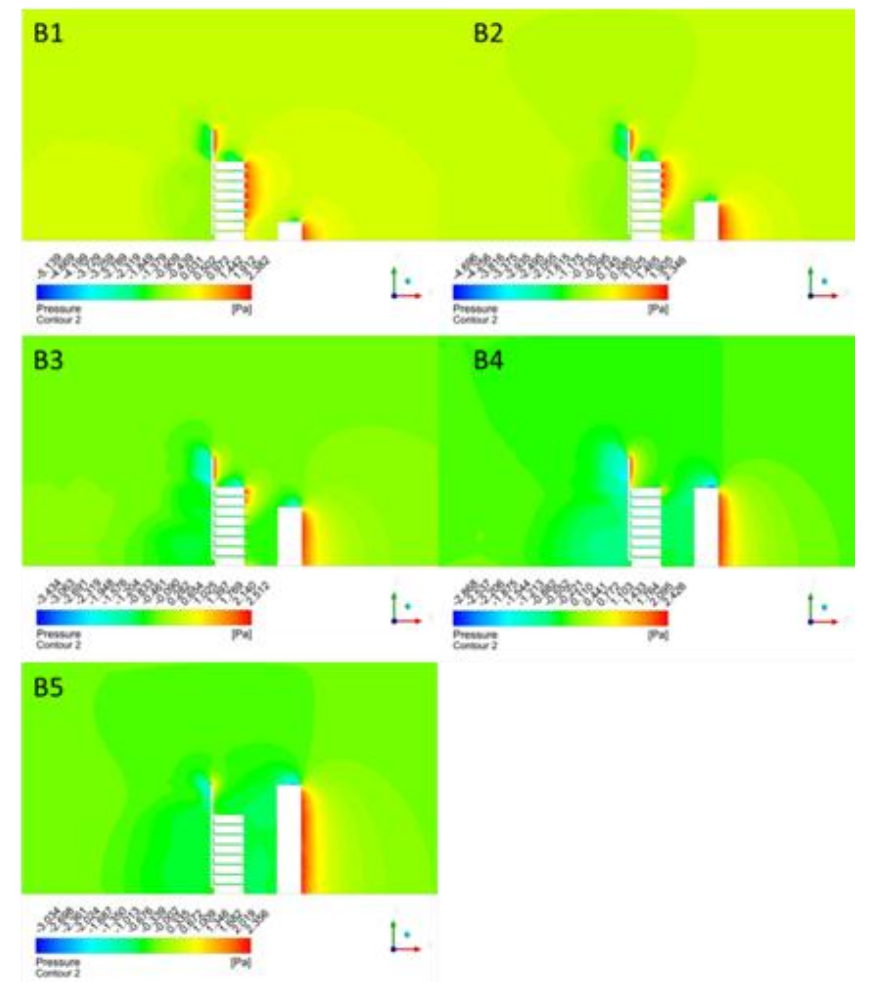

Fig 6. Pressure of ambient crosswind for building with SC with $12 \mathrm{~m}$ in front of inlet's obstacle B1 (two floors obstacle), B2 (four floors obstacle), B3 (six floor obstacle), B4 (eight floors obstacle), and B5 (chimney's height obstacle)

The Figure 6 above explains the contour compared to the amount of pressure due to the ambient crosswind from the positive $x$ to the negative $x$ at $2 \mathrm{~m} / \mathrm{s}$ with the obstacle $12 \mathrm{~m}$ from the front of the inlet. In figure B1 to B2, there is almost no difference; the pressure that occurs due to obstacle imaging tends to be high (almost close to $1 \mathrm{~Pa}$ ). The floor cleared by obstacle (floors which are not overshadowed by obstacle) will encounter pressure due to the crosswind. Put obstacle at $12 \mathrm{~m}$, still can decrease in SC performance in the building only by $10-15 \%$. For the pressure outside inlet area, $\mathrm{B} 4$ and $\mathrm{B} 5$ pressure images occur below $0 \mathrm{~Pa}$ (minus), and certainly will reduce SC performance by $17 \%$. From all obstacle height (B1-B5), the maximum wind velocity that can be produced at the SC's outlet reach $1.96 \mathrm{~m} / \mathrm{s}$ while the wind velocity in the room can reach an average of $0.48 \mathrm{~m} / \mathrm{s}$. This result close to the optimum average wind velocity induced by SC without obstacle, which is $0.69 \mathrm{~m} / \mathrm{s}$. The average success of $0.48 \mathrm{~m} / \mathrm{s}$ is due to better clearance than obstacle A (3 m). 


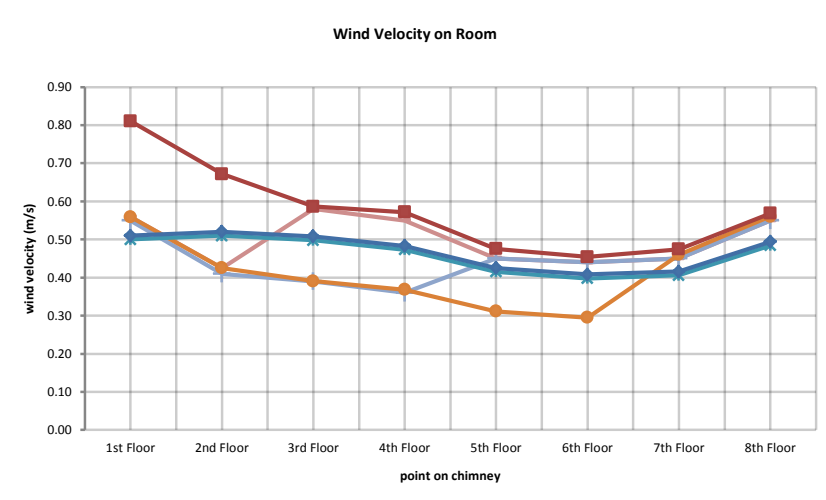

Fig 7. Graphic average wind velocity in building with SC with $12 \mathrm{~m}$ in front of inlet's obstacle

The Figure 7 above explains the previous paragraph, the performance of SC in a building when it induces wind when the obstacle is $12 \mathrm{~m}$ from the inlet. SC performance tends to be good when the obstacle building only blocks six floors (B1 - B3). Its performance tends to be stable when the obstacle blocks the inlet from 8 floors (B4 \& B5) even though it is still below the SC performance without obstacle. The wind speed is stable if the eight inlets almost covered by the shadow obstacle, on average, reaching $0.5 \mathrm{~m} / \mathrm{s}$.

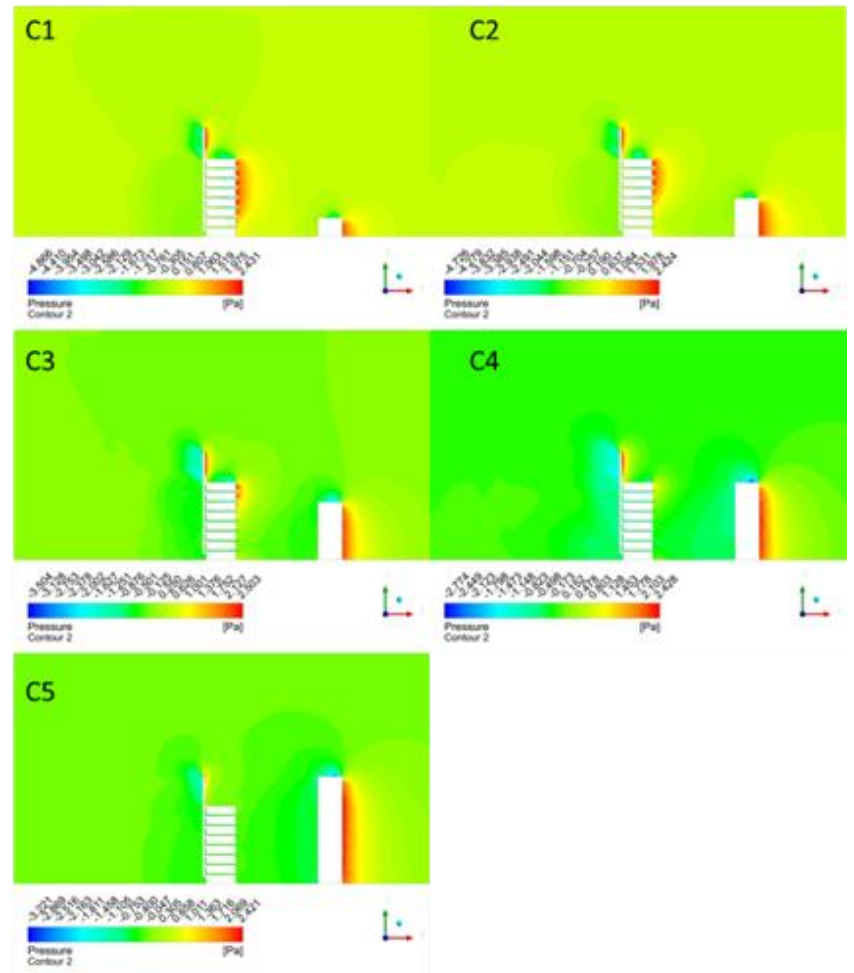

Fig 8. Pressure of ambient crosswind for building with SC with 24 $\mathrm{m}$ in front of inlet's obstacle C1 (two floors obstacle), C2 (four floors obstacle), C3 (six floor obstacle), C4 (eight floors obstacle), and C5 (chimney's height obstacle)

In the third experiment, the $24 \mathrm{~m}$ 's clearance obstacle in front of the inlet as in the Figure 8 above explains the contour of the magnitude of pressure due to the ambient crosswind from the positive $x$ to the negative $x$ at $2 \mathrm{~m} / \mathrm{s}$ with the obstacle $24 \mathrm{~m}$ from the front inlet or $2 \mathrm{x}$ the width of the building. In figure $\mathrm{C} 1$ to $\mathrm{C} 2$, there is almost no difference; the pressure that occurs due to obstacle imaging tends to be high (almost close to $1 \mathrm{~Pa}$ ). While the without obstacle parts (floors that are not overshadowed by obstacle) encounter pressure due to the ambient crosswind. As a result of the obstacle imaging at $24 \mathrm{~m}$, this still results in a decrease in SC performance in the building by $2-3 \%$. In the $\mathrm{C} 4$ and $\mathrm{C} 5$ pressure images that occur are actually under $0 \mathrm{~Pa}$ (minus), and certainly will reduce SC performance by $3 \%$.

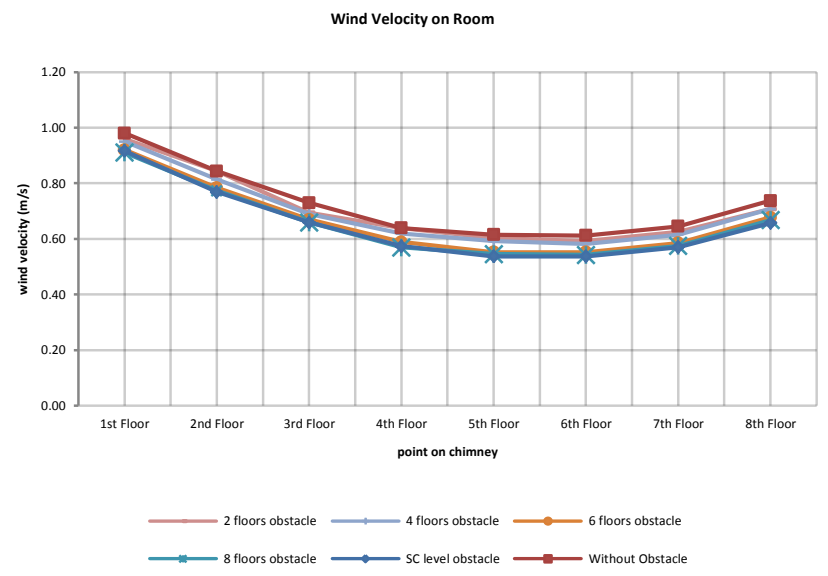

Fig 9. Graphic average wind velocity in building with SC with $24 \mathrm{~m}$ in front of inlet's obstacle

The Figure 9 above explains the previous paragraph, the performance of $\mathrm{SC}$ in a building when it induces wind when the obstacle is $24 \mathrm{~m}$ from the inlet. SC performance can be said to be well close to SC performance without obstacle. From the total obstacle height, the maximum wind velocity that can be produced at the end of the SC is only $2.05 \mathrm{~m} / \mathrm{s}$ while the wind velocity in the space can reach an average of $0.66 \mathrm{~m} / \mathrm{s}$. This result has approached the optimum average wind velocity induced by SC of $0.69 \mathrm{~m} / \mathrm{s}$. The average success of $0.66 \mathrm{~m} / \mathrm{s}$ is due to a clearance that is better than the obstacle B (12 m), even almost having an obstacle is not significant at a clearance of $24 \mathrm{~m}$.

From three experiments above, it is clear while putting the obstacle at a clearance of $24 \mathrm{~m}$ is the best option. However, realistically with the condition of building density in Jakarta, the optimum clearance of in front of the inlet 12 $\mathrm{m}$. For the building height that should be required for the obstacle in front of the inlet, the best is 2-4 floors. However, the height of 8 more floors is not problematic as long as the clearance is more than $12 \mathrm{~m}$ or more than half the width of the building.

The results of the above experiments raise a discussion regarding the rules for building free clearance in DKI Jakarta. The result above slightly contradictory with the regional Jakarta regulation: Guidelines for Urban Technical Details on DKI Jakarta for Single Type Buildings (based on Regional Regulation (Perda) No. 4 of 1975 and Governor Decree (Surat Keputusan Gubernur) No. 678 of 1994). The Figure 10 below states that the free clearance of buildings for the height of the 8-story building is only $7.5 \mathrm{~m}$, while the free clearance of $12 \mathrm{~m}$ only obtained after the building reaches a height of 17 floors. Indeed this regulation only 
binds to the minimum clearance for surrounding buildings; it is not necessary that the inlet clearance with the obstacle must have exactly $12 \mathrm{~m}$. Furthermore, determining how much clearance to use depends on-site availability.

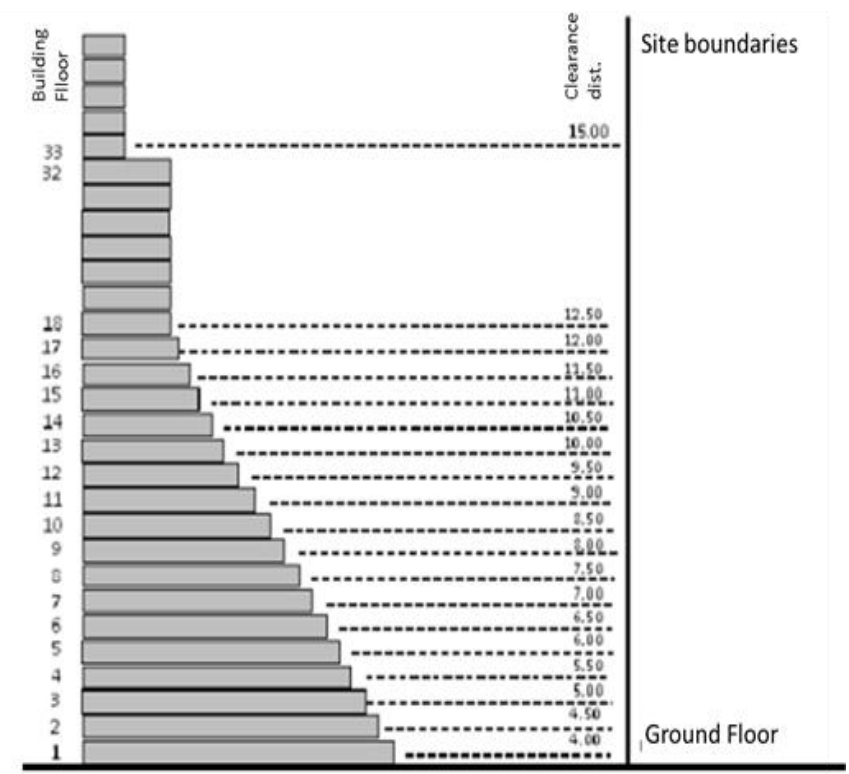

Fig 10. Building to building clearance distance regulation in Jakarta[23]

\section{CONCLUSION}

After Simulation of several obstacle variations and ambient crosswind related to the use of vertical solar chimney on office building prototypes has been carried out. Geometric model SC in office building medium-rise prototypes with mathematical models that describe fluid flow, and heat transfer of the system. Distribution of fluid flow, temperature, and pressure are also presented and analyzed. All simulation results are compared with buildings with SC without obstacle to analyze the effects by using obstacle. Associated with the ambient crosswind, the decreasing of performance did occur but it was not significant. The reduction in SC performance is only around $5-6 \%$. in addition, there is also a negative air flow on the north side of the building (negative $\mathrm{X}$-axis).

Regarding the building's free clearance, placing the obstacle in front of the inlet will certainly affect the performance of wind induction towards the space. The regional regulation has set the clearances for 8-storey buildings to be $7.5 \mathrm{~m}$, this can be interprete that with a distance of $7.5 \mathrm{~m} \mathrm{SC}$ performance is better than a distance of $3 \mathrm{~m}$, but it is better if you still use the effective clearance of $12 \mathrm{~m}$.

In the future, research is needed again on the free distance in front of the inlet, especially if there is absolutely no clearance, and whether it is possible to use SC in the building as a pollution removal.

\section{ACKNOWLEDGMENT}

This paper is prepared under the guidance from Tingzhen Ming, Ph.D., Professor Ph.D.'s assignment, Doctoral Program, Department of Built Environment and Energy Engineering, School of Civil Engineering and Architecture, Wuhan University of Technology.

\section{NOMENCLATURE}

\begin{tabular}{|c|c|c|c|}
\hline$A$ & Area $(\mathrm{m} 2)$ & $Q$ & $\begin{array}{l}\text { Heat gain of the air in the } \\
\text { collector (W) }\end{array}$ \\
\hline$A c$ & $\begin{array}{l}\text { Cross sectional area of } \\
\text { solar chimney }(\mathrm{m} 2)\end{array}$ & $z$ & Axial coordinate $(\mathrm{m})$ \\
\hline Acoll & Solar collector area (m2) & \multicolumn{2}{|c|}{ Greek Symbols } \\
\hline$C_{p}$ & $\begin{array}{l}\text { Specific heat capacity } \\
(\mathrm{J} / \mathrm{kg} / \mathrm{K}) \mathrm{D}\end{array}$ & b & $\begin{array}{l}\text { Volumetric coefficient of } \\
\text { expansion }(k-1)\end{array}$ \\
\hline$g$ & $\begin{array}{l}\text { Gravity acceleration (msec- } \\
\text { 2) }\end{array}$ & $\lambda$ & $\begin{array}{l}\text { Thermal conductivity } \\
(\mathrm{W} / \mathrm{m} / \mathrm{k})\end{array}$ \\
\hline G & Solar irradiance $(\mathrm{W} / \mathrm{m} 2)$ & $\varepsilon$ & Emissivity \\
\hline$H$ & Chimney height $(\mathrm{m})$ & $\rho$ & Density (kg/m3) \\
\hline$h$ & $\begin{array}{l}\text { Distance from the ground } \\
\text { to the cover }(\mathrm{m})\end{array}$ & $\tau_{\alpha}$ & $\begin{array}{l}\text { Transmittance- } \\
\text { absorbtance product }\end{array}$ \\
\hline hconv & $\begin{array}{l}\text { Heat-transfer coefficient } \\
(\mathrm{W} / \mathrm{m} 2)\end{array}$ & $a$ & Ambient \\
\hline$m$ & Mass flow rate (kg/sec) & $c$ & Cover \\
\hline$p$ & Pressure $(\mathrm{Pa})$ & coll & Collector \\
\hline$q$ & Solar radiation $(\mathrm{W} / \mathrm{m} 2)$ & $\mathrm{Ch}$ & Chimney \\
\hline$T$ & Temperature $(\mathrm{K})$ & 1 & \\
\hline$u$ & $\begin{array}{l}\text { Velocity in the radial } \\
\text { direction (msec- } 1 \text { ) }\end{array}$ & 2 & Outlet \\
\hline$v$ & $\begin{array}{l}\text { Velocity in the axial } \\
\text { direction (msec- } 1 \text { ) }\end{array}$ & $\Delta p$ & Pressure difference (Pa) \\
\hline V1 & $\begin{array}{l}\text { Inlet air velocity of the } \\
\text { solar collector }(\mathrm{m} / \mathrm{sec})\end{array}$ & $\Delta T$ & $\begin{array}{l}\text { Temperature increase } \\
\text { between outlet and inlet } \\
\text { of the collector }(\mathrm{K})\end{array}$ \\
\hline V2 & $\begin{array}{l}\text { Outlet air velocity of the } \\
\text { collector }(\mathrm{m} / \mathrm{sec})\end{array}$ & $\Phi p$ & $\begin{array}{l}\text { Heat losses by convection } \\
(\mathrm{W} / \mathrm{m})\end{array}$ \\
\hline
\end{tabular}

\section{REFERENCES}

[1] C. Vidiyanti, "Kajian Retrofit Bangunan sebagai Upaya Mereduksi Konsumsi Energi Operasional Studi Kasus: Campus Centre (Cc) Barat Itb," Vitruvian, vol. 5, no. 1.

[2] A. D. Sulistiowati, "KEANDALAN BANGUNAN RUMAH SUSUN STUDI KASUS: RUMAH SUSUN SARIJADI BANDUNG," Arsitron, vol. 9, no. 01, pp. 1-9, 2019.

[3] M. S. Hidayat, "Implementation of Green Building Concept in Commercial Buildings: Malls and Trade Center in Jakarta," International Journal of Architecture and Urban Development, vol. 6, no. 4, pp. 21-29, 2016.

[4] S. Stevanović, "Optimization of passive solar design strategies: A review," Renewable and Sustainable Energy Reviews, vol. 25, pp. 177-196, 2013.

[5] P. Satwiko, N. Locke, and M. Donn, "REPRODUCING THE REAL PRESSURE COEFFICIENT USING A COMPUTATIONAL FLUID DYNAMICS PROGRAM HOW CLOSE IS CLOSE ENOUGH?," in Proceedings of the 32th Annual Conference of the Australia and New Zealand Architectural Science Association, 1998, pp. $15-17$.

[6] L. N. Groat and D. Wang, Architectural research methods. John Wiley \& Sons, 2013.

[7] M. Shameri et al., "Daylighting characterstics of existing double-skin façade office buildings," Energy and Buildings, vol. 59, pp. 279-286, 2013.

[8] E. Gratia and A. De Herde, "Greenhouse effect in double-skin facade," Energy and buildings, vol. 39, no. 2, pp. 199-211, 2007. 
[16] S. A. Hassanein and W. A. Abdel-Fadeel, "Improvement of natural ventilation in building using multi solar chimneys at different directions," Journal of Engineering Sciences, vol. 40, no. 6, pp. 1661-1677, 2012.

[17] W. Ding, Y. Hasemi, and T. Yamada, "Natural ventilation performance of a double-skin façade with a solar chimney," Energy and Buildings, vol. 37, no. 4, pp. 411-418, 2005.

[18] M. Jin, R. E. Dickinson, and D. Zhang, "The footprint of urban areas on global climate as characterized by MODIS," Journal of climate, vol. 18, no. 10, pp. 1551-1565, 2005.

[19] M. Santamouris, C. Cartalis, A. Synnefa, and D. Kolokotsa, "On the impact of urban heat island and global warming on the power demand and electricity consumption of buildings-A review," Energy and Buildings, vol. 98, pp. 119-124, 2015.

[20] S. Abraham and T. Ming, "Numerical analysis on the thermal performance of a building with solar chimney and double skin façade in tropical country," in IOP Conference Series: Materials Science and Engineering, 2018, vol. 453, no. 1: IOP Publishing, p. 012030.

[21] J. W. Creswel, "Research design: Qualitative, quantitative, and mixed methods approaches," Los angeles: University of Nebraska-Lincoln, 2009.

[22] M. Tingzhen, L. Wei, X. Guoling, X. Yanbin, G. Xuhu, and P. Yuan, "Numerical simulation of the solar chimney power plant systems coupled with turbine," Renewable energy, vol. 33, no. 5, pp. 897905, 2008.

[23] A. Sabaruddin, AZ Persyaratan Teknis Bangunan. GRIYA KREASI, 2011. 